\title{
SIDE EFFECTS OF DRUGS
}

\section{Lung changes associated with phenylbutazone treatment}

Lung disorders caused by the pyrazolones (which include phenylbutazone) are uncommon. Busulphan ${ }^{1}$ produces clinical and pathological changes closely resembling cryptogenic fibrosing alveolitis, and radiologically similar changes have been reported in the lungs of patients with rheumatoid arthritis. ${ }^{2}$ Patients receiving nitrofurantoin ${ }^{3}$ and para-amino salicylic acid ${ }^{4}$ develop similar radiological appearances, which might be described as eosinophilic pneumonias but may be the result of an immune response. We report here lung changes that seemed to be caused by phenylbutazone treatment.

\section{Case report}

A 69-year-old man was admitted semiconscious to the accident and emergency department. He gave a history of joint pains for which his GP had prescribed phenylbutazone $50 \mathrm{mg}$ three times a day for two weeks. On examination he had the stigmata of advanced myxoedema.

Special investigations showed: serum thyroxine less than $6 \mathrm{nmol} / 1$ $(0.47 \mu \mathrm{g} / 100 \mathrm{ml})$; haemoglobin $11.6 \mathrm{~g} / \mathrm{dl}$; erythrocyte sedimentation rate $21 \mathrm{~mm}$ in $1 \mathrm{~h}$; leucocyte count $8.2 \times 10^{8} / 1\left(8200 / \mathrm{mm}^{3}\right)$ with $2 \%$ eosinophils. Thyroid-stimulating hormone was over $128 \mathrm{mU} / 1$ (normal $<2.8 \mathrm{mU} / \mathrm{l}$ ) A chest radiograph showed only slight cardiac enlargement.

Thyroxine $0.05 \mathrm{mg}$ daily was started immediately and he made good progress without signs of heart failure. After two more days he complained of pain in the interphalangeal joints and was again given phenylbutazone. Over the next two weeks the patient became fully mobile, during which time the dose of thyroxine was maintained at $0.05 \mathrm{mg}$ daily.

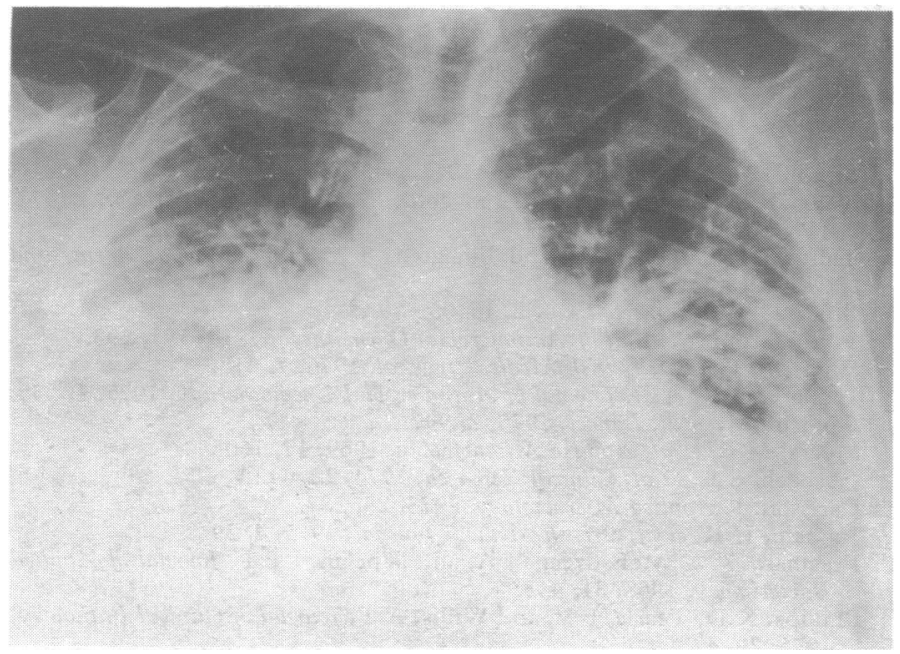

Abnormal shadowing affecting the whole of both lungs.

Eighteen days after admission he became semiconscious with extensive bilateral fine crepitations throughout the chest. Arterial $\mathrm{Po}_{2}$ was $6 \mathrm{kPa}$ $(45 \mathrm{~mm} \mathrm{Hg}), \mathrm{PCO}_{2} 13 \mathrm{kPa}(98 \mathrm{~mm} \mathrm{Hg})$, and arterial $\mathrm{pH} 7 \cdot 18$. A chest radiograph showed multiple, poorly defined, rounded shadows in both lungs. Intermittent positive pressure ventilation was started with a Cape ventilator. Over the next two weeks chest radiographs showed extension of the abnormal shadowing to affect the whole of both lungs (see figure), even though the patient himself felt better. He was never pyrexial. He had little sputum, and repeated cultures showed no pathogens. There was a leucocytosis of $20.1 \times 10^{9} / 1\left(20100 / \mathrm{mm}^{3}\right)$ with a fluctuating but gradually increasing eosinophilia, up to $14 \%$ of a total white cell count of $10.5 \times 10^{8} / 1(10500 /$ $\mathrm{mm}^{3}$ ). Because his clinical state suggested the presence of pulmonary oedema, frusemide and then ethacrynic acid were given without significant diuresis.

When it became clear that he did not have pulmonary oedema, we wondered whether the patient's lung changes were caused by one of his drugs. Fluorescent antibody studies were found to be strongly positive to thyroglobulin, thyroid microsomes, and smooth muscle. Thyroglobulintanned cells were positive to a titre of $1 / 250$, while Rose Waaler and Latex rheumatoid arthritis tests gave negative results.

Prednisone $10 \mathrm{mg}$ three times a day was started and phenylbutazone was stopped. The eosinophilia rapidly disappeared, the tissue antibodies disappeared, and he improved steadily although chest radiographs showed that the abnormal shadowing in the lungs resolved more slowly than his clinical state. Findings on lung function studies are shown in the table. A radiograph six and a half months later was completely normal, apart from the persistence of slight cardiac enlargement.

Results of lung function tests during course of reaction

\begin{tabular}{|c|c|c|c|}
\hline & $\begin{array}{c}\text { Predicted } \\
\text { normal }\end{array}$ & $\begin{array}{l}18 \text { Days after } \\
\text { start of } \\
\text { alveolitis and } \\
\text { before steroids }\end{array}$ & $\begin{array}{l}18 \text { Days after } \\
\text { start of } \\
\text { alveolitis, while } \\
\text { on steroids }\end{array}$ \\
\hline \multicolumn{4}{|c|}{ Spirometry } \\
\hline $\begin{array}{l}\text { Peak expiratory flow rate }(1 / \mathrm{min}) \\
\text { Forced vital capacity }(1) \\
\text { Forced expiratory yolume }\end{array}$ & $\begin{array}{l}596 \\
4 \cdot 37\end{array}$ & $\begin{array}{l}225 \\
1.37\end{array}$ & $\begin{array}{l}395 \\
2 \cdot 11\end{array}$ \\
\hline 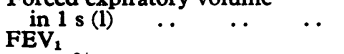 & $3 \cdot 22$ & $1 \cdot 14$ & 1.69 \\
\hline$\frac{W_{1}}{F{ }^{2}} \%$ & 74 & 83 & 80 \\
\hline $\begin{array}{l}\text { Maximum mid expiratory } \\
\text { flow rate (1/s) } \\
\text { Maximum mid inspiratory }\end{array}$ & $2 \cdot 39$ & 1.23 & 1.69 \\
\hline $\begin{array}{c}\text { flow rate }(1 / \text { s) } \\
\text { MMEFR:MMIFR }\end{array}$ & $\begin{array}{l}2 \cdot 98 \\
0.80\end{array}$ & $\begin{array}{l}1.30 \\
0.95\end{array}$ & $\begin{array}{l}1 \cdot 47 \\
1 \cdot 15\end{array}$ \\
\hline \multicolumn{4}{|c|}{ Lung volume } \\
\hline $\begin{array}{l}\text { Slow vital capacity }(1) . \\
\text { Functional residual capacity } \\
\text { Total lung capacity } \\
\text { Residual volume }\end{array}$ & $\begin{array}{l}4 \cdot 3 \\
2 \cdot 18 \\
7 \cdot 36\end{array}$ & $\begin{array}{l}1.59 \\
1.76 \\
2.96\end{array}$ & $\begin{array}{l}2 \cdot 20 \\
1.94 \\
3.37\end{array}$ \\
\hline 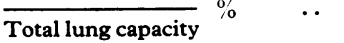 & 41 & 46 & 35 \\
\hline
\end{tabular}

\section{Comment}

The essence of this case is the nature of the changes in the lungs. There was no complete proof that the changes in the lungs were caused by phenylbutazone treatment. The two-week course prescribed by his family doctor caused no ill effects. When he developed physical signs suggestive of pulmonary oedema the radiological appearances, while atypical for pulmonary oedema, were consistent with this diagnosis. Despite active treatment to eliminate the oedema he deteriorated clinically and radiologically and nearly died. This failure to respond prompted us to consider the possibility of an underlying allergic lung disease. Phenylbutazone was stopped and steroids begun. At once he improved and lung changes began to resolve. The eosinophilia, which had gradually increased while he was on phenylbutazone, disappeared, as did the autoimmune antibodies that had been present in high titre. As the lungs cleared the radiological appearances became "typical" of allergic alveolitis.

Side effects from phenylbutazone therapy are common. ${ }^{5}$ Sodium and chloride are retained and urine volume reduced, which may lead to pulmonary oedema. Phenylbutazone may also cause hypersensitivity reactions of the serum sickness type, the toxic effects of the drug being more severe in the elderly. Nevins et $\mathrm{l}^{6}$ reported two cases of pulmonary oedema associated with phenylbutazone therapy. This was attributed to increased renal tubular absorption of sodium possibly mediated by the hypothalamus. Cameron ${ }^{7}$ described drug-induced lupus diathesis in a patient treated with phenylbutazone. The patient was dyspnoeic and fine crepitations were noted in the lungs, the erythrocyte sedimentation rate was raised, and antinucelar factor was present transiently in the serum. Neither rheumatoid factor nor lupus erythematosus cells were found. Phenylbutazone was stopped but no diuresis or loss of weight resulted. The patient's dyspnoea disappeared. When he was given a further challenging dose of the drug, breathlessness and crepitations recurred, despite diuretic therapy.

We suggest that the lung changes in our patient, the eosinophilia, and possibly the changes in the fluorescent antibodies were due to an immune response to phenylbutazone manifested particularly in the lungs. Possibly some of the cases of "rheumatoid lung" reported 
extensively elsewhere are due to hypersensitivity to phenylbutazone in patients who have received this drug.

1 Oliner, H, et al, American fournal of Medicine, 1961, 31, 134.

${ }^{2}$ Lee, F T, and Brain, A T, Lancet, 1962, 2, 693.

3 Roseroni, E C, and De Remee, R A, and Dires, D E, New England fournal of Medicine, 1968, 279, 1258.

4 Wold, D E, and Zahn, D W, American Review of Tuberculosis, 1956, 74, 445.

5 Goodman, L S, and Gilman, A, Pharmacological Basis of Therapeutics, 4th edn, $p$ 335. New York, Macmillan, 1971.

${ }^{6}$ Nevins, M, et al, Lancet, 1969, 2, 1358.

7 Cameron, D C, British Medical fournal, 1975, 2, 500.

\section{Westminster Hospital, London SW1P 2AP}

J G B THURSTON, MB, MRCP, senior medical registrar

P MARKS, MB, MRCP, senior house officer

D TRAPNELL, FRCP, FRCR, consultant radiologist

\section{Pemphigus foliaceus induced by penicillamine}

Penicillamine is being used increasingly in the management of rheumatoid arthritis. It is the treatment of choice in Wilson's disease and cystinuria, but, as both of these disorders are rare, only relatively few patients have received the drug. Rashes occur in up to $60 \%$ of patients with Wilson's disease and cystinuria on penicillamine..$^{1-3} \mathrm{~A}$ much lower incidence is reported in rheumatoid arthritis (13-25\%), possibly because smaller doses are given and the drug is introduced more cautiously. ${ }^{4}$

Morbilliform and urticarial eruptions are the most common lesions and they usually appear within the first 10 days of treatment. Withdrawing treatment leads to prompt recovery and the drug can usually be reintroduced without the rash recurring. Blistering and bruising with wrinkled scars and milia may occur on areas exposed to pressure and injury in patients with Wilson's disease or cystinuria, usually after the first year of treatment. ${ }^{5} 6$ Such lesions, as well as elastosis perforans serpiginosa, ${ }^{7}$ are probably related to penicillamine's lathyrogenic effects on connective tissues; they improve if the dose is reduced.

Rheumatologists are familiar with another "late eruption": raised, irregular, scaly plaques, which are extremely itchy and are mostly situated on the trunk. ${ }^{4} 8$ They appear after about six months of treatment, are unresponsive to topical steroids, and take many weeks to disappear after the drug is discontinued.

Pemphigus occurring during penicillamine treatment of Wilson's disease was first reported in France and later shown to occur in rheumatoid arthritis. ${ }^{9-11}$ The patient may have pemphigus vulgaris or pemphigus foliaceus, and most improve when penicillamine is withdrawn. In some cases, however, the rash persists and is difficult to control. Since then this complication has become well recognised by British dermatologists. ${ }^{12} \mathrm{We}$ describe here seven patients who developed pemphigus.

\section{Case reports}

The two men and five women (aged 46-65), who had long-standing seropositive rheumatoid arthritis, poorly controlled by analgesics, prednisolone (in six cases), and gold (in four cases), were given penicillamine. In six the initial dose of penicillamine was $250 \mathrm{mg}$ /day increasing by $250 \mathrm{mg}$ each month to $750 \mathrm{mg} /$ day; one patient received $500 \mathrm{mg} /$ day throughout. After six to 12 months' treatment they complained of an itchy rash and the drug was discontinued

Case 1-A 46-year-old woman had scaly plaques, some with central or peripheral vesicles, on the abdomen. After five months numerous smal blisters suddenly appeared (see figure). Skin biopsy showed subcorneal blister with moderate acantholysis and dermal perivascular infiltrate of lymphocytes and neutrophils. Serum epithelial antibody titre was $1 / 10$, and she was positive for antinuclear factor (ANF) (IgG and IgM). The eruption has persisted for a year despite prednisolone and azathioprine.

Case 2-Erythematous lesions with marked peripheral scaling were first seen on the trunk in this 51-year-old man; four months later the eruption became extensive with blistering. Skin biopsy showed subcorneal blister, no
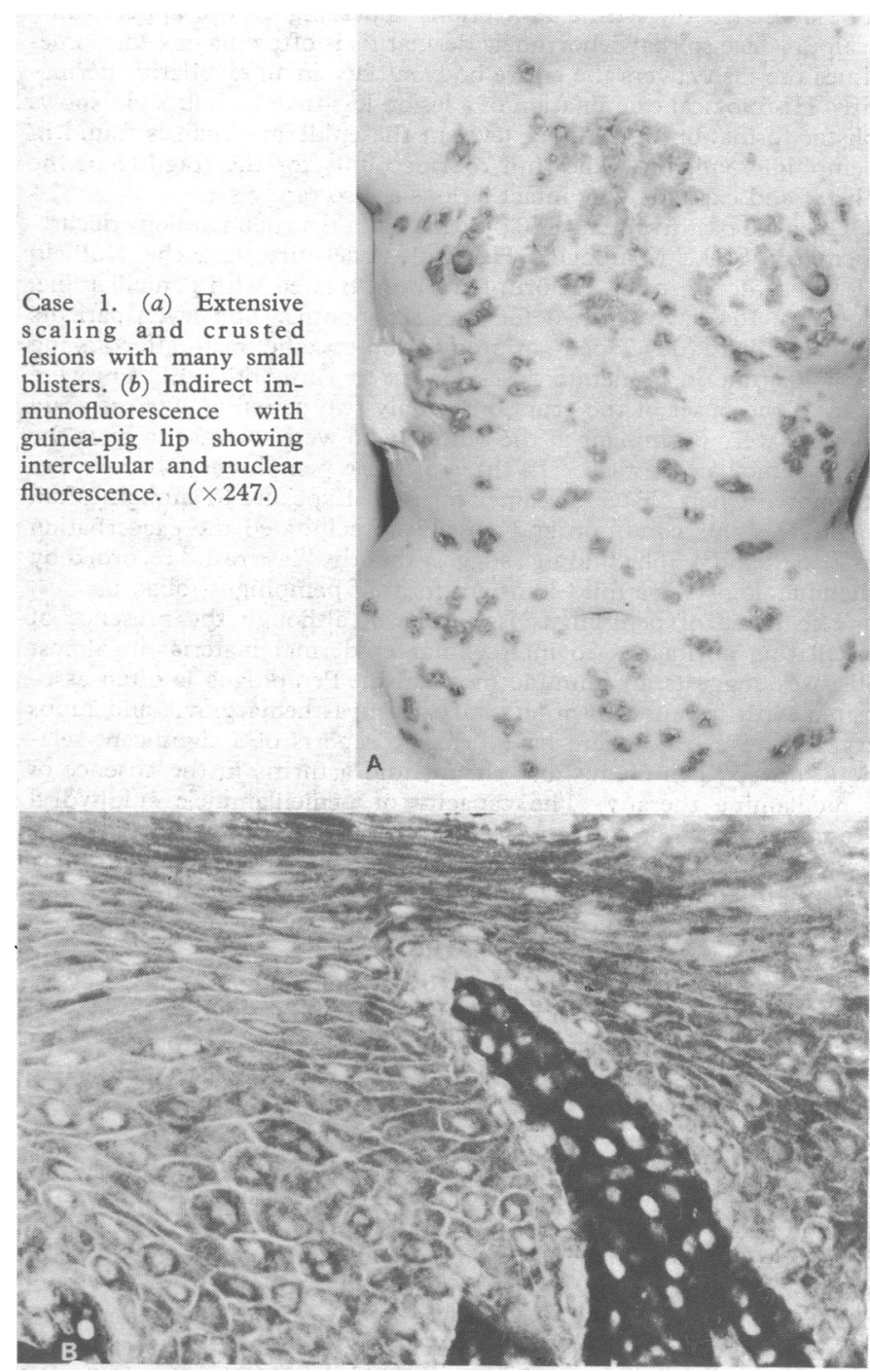

acantholysis, and dermal perivascular infiltrate of neutrophils. Epithelial antibody titre was 1/10 and he was negative for ANF. The rash has been present for 23 months in spite of $20-30 \mathrm{mg}$ prednisolone daily.

Case 3-This 59-year-old woman had a few small blisters and scaly lesions on the trunk and scalp. Skin biopsy showed subcorneal blister, no acantholysis, and moderate perivascular infiltrate. She was negative for ANF. Epithelial antibody titre was $1 / 10$, and smooth muscle antibody was present. Sepharose 6B filtration studies showed circulating IgG immune complexes. The rash, which has been present for five months, was improving with topical corticosteroids at the time of writing.

Case 4-This 65-year-old woman, who had severe digital vasculitis associated with rheumatoid arthritis, had several scaly lesions on the neck and later developed blisters. Skin biopsy showed epidermal ulceration and infiltration of the dermis by neutrophils. She was positive for ANF (IgM), and direct immunofluorescence of paralesional skin showed epidermal intercellular fluorescence. Four months after the lesions had healed with topical steroids the patient developed digital gangrene and penicillamine was restarted. The rash did not return although epithelial antibody was present in the serum (titre $1 / 10$ ).

Cases 5, 6, and 7-Two patients had annular scaly lesions, while the third had small blisters which turned into crusts. Within eight weeks of stopping penicillamine all were free of lesions. Colour photographs were examined by dermatologists, who considered that the lesions were consistent with a diagnosis of pemphigus foliaceus. Penicillamine was reintroduced in one patient without recurrence of the rash, but the drug was finally withdrawn because of thrombocytopenia. Eighteen months later the patient died from Goodpasture's syndrome.

\section{Comment}

The term pemphigus refers to a group of uncommon blistering diseases which can affect all ages. ${ }^{13}$ Pemphigus vulgaris, with its easily recognised blistering of the skin, is the best known. The much rarer pemphigus foliaceus is notoriously difficult to diagnose because blisters are not as obvious and leafy scales and crusts predominate. 